1

\title{
cultivar and defoliation severity \\ Root production in a subtropical pasture is mediated by
}

${ }^{1}$ Agronomy Department, University of Florida, Gainesville, FL, USA.

${ }^{2}$ Range Cattle Research and Education Center, University of Florida, Ona, FL, USA.

*Corresponding Author: chwilson@ufl.edu

I These authors contributed equally to this work

\& These authors also contributed equally to this work

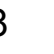

(1)

Chris H. Wilson $^{1 * \pi}$, Joao M. Vendramini2\&, Lynn E. Sollenberger ${ }^{1 \&}$, S. Luke Flory $^{1 \uparrow}$ 


\section{Abstract}

33 Background. Grasslands occupy significant land area and account for a large proportion of the

34 global soil carbon stock, yet the direct effects of grazing and genotypic composition on

35 relationships between shoot and root production are poorly resolved. This lack of understanding

36 hinders the development of models for predicting root production in managed grasslands, a

37 critical variable for determining soil carbon stocks.

38 Methods. We quantified the effects of season-long defoliation treatments on both shoot and root

39 production across four cultivars of a widely-planted pasture grass species (Paspalum notatum

40 Fluegge) in a common garden setting in South Florida, USA.

41 Results. We found that infrequently applied (4 week) severe defoliation (to $5 \mathrm{~cm}$ ) substantially

42 enhanced shoot production for all cultivars, while severe defoliation reduced root production

43 across cultivars, regardless of frequency. Overall, cultivars varied substantially in root

44 production across the range of defoliation treatments in our study. However, there was no

45 significant relationship between shoot and root production.

46 Conclusions. Our results find that aboveground and belowground productivity are only weakly

47 coupled, suggesting caution against use of simple aboveground proxies to predict variations in

48 root production in grasslands. More broadly, our results demonstrate that improved modeling and

49 management of grasslands for belowground ecosystem services, including soil carbon

50 sequestration/stocks, will need to account for intraspecific genetic variations and responses to

51 defoliation management. 


\section{Introduction} large proportion of the global SOC stock $(1,2)$. However, there is considerable uncertainty in

61 predictions of net ecosystem exchange, and hence carbon sequestration services from grasslands

$62(3,4)$. One significant source of uncertainty is that while large herbivore grazing is known to

63 mediate patterns of plant species composition, diversity, and aboveground primary productivity

64 (5-7), the effects of grazing on belowground processes and soil carbon is less clear (8-11). In

65 particular, there are limited field studies where the impact of grazing on root production in

66 grassland systems has been directly measured (e.g., via root ingrowth cores or minirhizotron

67 technology, but see Ziter and MacDougall (12) Balogianni et al. (11) and Cooley et al. (13)).

68 Since belowground production may be the largest component of total NPP for many grasslands

$69(14,15)$, determining how grazing affects root production will help to predict if and when

70 grassland ecosystems will behave as carbon sinks, and whether grazing is likely to promote or

71 inhibit carbon sequestration services.

73 compared with shoot carbon (16-18), and are especially critical in grassland ecosystems where

74 aboveground tissue is susceptible to frequent removal by fire and grazing (19). Current

75 understanding of how grazing affects root production is ambiguous. For example, one temperate

76 mesocosm study showed that intense defoliation inhibited root production and accelerated the

77 loss of SOC (20), whereas some field studies have documented greater belowground allocation

78 and root production under grazing (Hafner et al. (21) in the Tibetan plateau; Wilson et al. (22) in

79 subtropical pasture).. Augustine et al. (23) found that defoliation reduced belowground carbon

80 allocation in one grazing-adapted North American grass species (Pascopyrum smithii, western 
81 wheatgrass) but not in another (Bouteloa gracilis, blue grama), highlighting interspecific

82 variations in response to a given defoliation regime. In general, laboratory and mesocosm studies

83 have found that frequent grazing/defoliation leads to declines in standing root biomass over the

84 long term (24), whereas a global synthesis of data comparing grazed and ungrazed grasslands

85 found a mix of positive and negative effects on standing root biomass (25). Overall, this

86 discordance suggests that variations in plant composition, underlying environmental factors,

87 grazing intensity, or some combination of these factors significantly mediate the effect of grazing

88 on root production.

89 Grazing effects on belowground production may not only vary based on plant species, but

90 also on the genotypic composition of a grazed stand, given the increasing evidence of the

91 importance of intraspecific variation in driving ecosystem structure and function (26,27). In

92 general, some literature suggests that reduced root allocation (and increased shoot allocation)

93 following grazing may represent an evolutionarily adaptive trait for grazing tolerance (28). For

94 instance, Carman (1985) (29) noted that short-leaved genotypes of Schizachyrium scoparium,

95 selected from a long-term grazed site, exhibited lower rates of root elongation post-grazing than

96 longer-leaved genotypes from a long-term grazing excluded site. Planted pasture grasses also

97 have been shown to exhibit genotypic variability in shoot and root production in response to

98 grazing (e.g. Dawson et al. (30)). For example, Interrante et al. (31) observed significantly less

99 plant cover in recently selected, upright-growing Paspalum notatum (bahiagrass) cultivars in

100 response to severe, frequent defoliation, but did not observe less cover with the same defoliation

101 treatments applied to widely naturalized cultivars, suggesting significant intraspecific variability

102 in grazing tolerance and belowground allocation. 
Although root production is a critical component of predicting the carbon cycle in

104 grassland ecosystems, it is difficult to monitor or predict over large spatial scales. Thus, regional-

105 scale grassland models have been developed that predict total NPP and/or greenhouse gas

106 exchange on the basis of aboveground canopy characteristics estimated from remote sensing

107 (32-34). Similarly, some previous work has sought to predict BNPP on the basis of readily

108 obtained aboveground measurements in both grasslands (14) and forests (35). Recently,

109 concerted efforts have been made to link fine root traits with other plant traits, across species and

110 environments, by compiling and analyzing global-scale big datasets (36). The goal is to have

111 reliable aboveground proxies for predicting critical belowground root processes (37). However,

112 given the evidence for potentially significant genotypic and defoliation effects on belowground

113 carbon allocation, it is unclear whether aboveground proxies can ever reliably approximate root

114 production. Given the central importance of root system carbon inputs to maintaining SOC,

115 especially in grasslands, we need more data from experimental systems where genotypic

116 composition and grazing management have been manipulated, and the relationship between

117 above and belowground allocation have been quantified.

118 In this study, we tested the independent and combined effects of defoliation intensity and

119 frequency, and cultivar on root production of a widely utilized pasture grass species of the

120 southeastern United States, Paspalum notatum Flüegge (bahiagrass). For Bahiagrass, we can

121 broadly delineate cultivars on the basis of growth habit where historically older, widely

122 naturalized cultivars tend to have a more prostrate growth pattern, whereas recently selected

123 cultivars tend to have a more upright growth pattern, reflecting selection for improved forage

124 growth characteristics (38). Previous work, and considerable producer experience, suggests that

125 bahiagrass has a remarkable resilience to intense grazing, wherein forage growth and quality is 
maximized with severe defoliation (close to ground level) so long as regrowth intervals are adequate $(39,40)$. However, the impact of defoliation severity on root production across

128 cultivars, and their associated growth habits, has not been directly studied, reflecting a general

129 lack of information on belowground growth responses in warm season subtropical pasture (13).

130 To redress this gap in knowledge we conducted an experiment in a common garden setting under

131 realistic conditions of limited soil fertility to isolate the effects of defoliation intensity, frequency

132 and cultivar on belowground production, and to evaluate the relationship between aboveground

133 and belowground growth.

134 Consistent with the literature on compensatory growth responses from natural and

135 planted pastures (40-42), and the literature on genotypic variability (e.g. Dawson et al. (30)) we 136 hypothesized that:

137 1) Severe defoliation, applied infrequently, would stimulate increases in aboveground primary productivity (via compensatory response mechanisms), but would have neutral effects on root productivity across all cultivars; production across all cultivars as a consequence of plant requirements to prioritize photosynthate allocation to regrowing shoots; reductions in root production under severe defoliation compared to the more upright cultivars, reflecting a beneficial adaptation for increased shoot allocation following severe defoliation events; and 
correlate at the plot level reflecting variations in underlying soil factors determining total productivity.

\section{Materials \& Methods} plant cultivar on root production, we established $323 \mathrm{~m} \mathrm{x} 7 \mathrm{~m}$ experimental plots at the University of Florida Range Cattle Research and Education Center, Ona, FL $\left(27^{\circ} 26^{\prime}\right.$ N, $82^{\circ} 55^{\prime} \mathrm{W}$ ) in 2009 . The soils were uniform and classified as Pomona fine sand (sandy, siliceous, hyperthermic Ultic Alaquod). First, we seeded plots with one of four bahiagrass cultivars (Argentine, Pensacola, Tifton-9, and UF-Riata). Bahiagrassis a perennial C4 pasture grass with improved germplasm that was introduced to Florida in the 1920s from South America and constitutes the primary forage for the Florida cow-calf industry (43). 'Argentine' and 'Pensacola' are widely-distributed, naturalized cultivars in the state of Florida with a decumbent growth habit, whereas 'Tifton-9' and 'UF-Riata' are recently-released cultivars selected for improved agronomic characteristics including more upright growth habits and less photoperiod sensitivity

165 (31,38). Plots were fully established by the onset of the 2010 summer growing season with complete, uniform plant cover. More details, including soil fertility characteristics can be found

167 in Vendramini et al. (38). Site weather data for this period were accessed from the Florida Automated Weather Network (FAWN, http://fawn.ifas.ufl.edu/data/), including temperature, 169 precipitation, and evapotranspiration, and all fell within normal ranges (Table A1).

171 weeks later on October $5^{\text {th }}$ 2013. Although we did not measure soil moisture, the soils were all 
173 soils (43). We therefore assumed that plant growth was not limited by water availability during

174 the sampling period, or at the very least that water availability was essentially constant across

175 plots. Each plot $(n=32)$ was randomly assigned to either a frequent ( 2 week) or infrequent (4

176 week) defoliation treatment to simulate grazing stress. Each plot was divided in half and received

177 two defoliation intensities (a severe defoliation to $5 \mathrm{~cm}$ residual height, and a mild defoliation to

$17815 \mathrm{~cm}$ residual height) resulting in $\mathrm{n}=64$ experimental units (Figure A1). Thus, our design was

179 effectively split-plot with two main-plot treatments (cultivar and defoliation frequency), while

180 our subplot factor was defoliation intensity. Overall, each cultivar X defoliation severity X

181 defoliation frequency treatment was replicated 4 times.

We harvested a $0.92-\mathrm{m}^{2}$ quadrat from each subplot during each defoliation treatment with

183 a rotary mower (Sensation Mow-Blo Model 11F4-0) at the target cutting heights: $5 \mathrm{~cm}$ for the

184 severe defoliation, $15 \mathrm{~cm}$ for the mild defoliation, values chosen based on personal observation

185 (C.H. Wilson, L.E Sollenberger, J.M. Vendramini) to represent the extremes of pasture

186 defoliation under grazing by beef cattle in Florida. To quantify aboveground production,

187 harvested material was oven-dried at $60^{\circ} \mathrm{C}$ to constant mass and weighed on an analytical scale.

188 During the final harvest, all subplots were harvested at $5 \mathrm{~cm}$. Total aboveground production was

189 determined by summing values for each subplot across all dates including the final harvest.

190 Aboveground production values are presented in $\mathrm{gm}^{-2}$ (dry biomass).

To quantify root primary production in response to the defoliation treatments, we

192 installed 2-mm mesh root in-growth cores (44) on June $7^{\text {th }}, 2013$, prior to imposing the

193 defoliation treatments. Cores were $7.5 \mathrm{~cm}$ diameter x $25 \mathrm{~cm}$ deep and constructed of fiberglass

194 mesh. They were installed by first excavating a cylinder of soil with a soil auger to target

195 dimensions, placing the mesh bags into the cylinder so that the upper edge of the bags was just 
below the soil surface, and then re-filling the cores with sieved, root-free soil from the same plot.

197 We retrieved the cores at the end of the growing season on October 5th 2013, 16 weeks after

198 installation. The final volume of soil contained in each core was quantified prior to washing the

199 roots free of soil on a $250-\mathrm{uM}$ sieve. Root samples were then oven-dried at $60^{\circ} \mathrm{C}$ to constant

200 mass and weighed on an analytical scale. To correct for variation in core volume, root biomass

201 was multiplied by a correction factor determined as the inverse of the ratio of each core volume

202 to a reference core (a cylinder of $7.5 \mathrm{~cm}$ diameter and $25 \mathrm{~cm}$ depth). Finally, we visually

203 determined that almost all root biomass was contained within the depth we evaluated (i.e. $25 \mathrm{~cm}$

204 depth) by digging several test pits around our study area. We note from personal observation that

205 wet pastures tend to result in shallower root distribution, consistent with early literature such as

206 (45). Therefore, we multiplied root biomass by a constant $\left(10000 /\left(\mathrm{pi}^{*} 3.75^{\wedge} 2\right)\right)$ to convert our

207 measures to $\mathrm{g} / \mathrm{m}^{2}$, putting them on an easily interpretable scale.

208

209 Statistical Analysis

210 Response variables for analyses were shoot and root production, and a measure of root

211 allocation defined as:

Root production

$\overline{\text { Root production }+ \text { Shoot production }}$

213 To analyze among-cultivar variability in response to our treatments, we parameterized a

214 varying-intercept/varying-slope Bayesian hierarchical model that we applied to both of our

215 response variables. In this model, we estimate intercept and slope (i.e., treatment effects)

216 coefficients for each cultivar, where each batch of coefficients is modeled as a draw from a

217 normal distribution with an estimated variance component (46). We included binary predictor

218 variables using a $-0.5 / 0.5$ "effect coding" for our experimentally imposed treatments: lenient (15 
$\mathrm{cm})$ and infrequent ( $4 \mathrm{wk})$ defoliation were assigned -0.5 values, while frequent $(2 \mathrm{wk})$ and severe $(5 \mathrm{~cm})$ defoliation were assigned 0.5 values. Under this coding, the model intercept

221 represents the grand mean, and the coefficients for defoliation severity and frequency represent

222 the main effects of severe and/or frequent defoliation across both levels of the other treatment

223 (see e.g. Schabenberger et al. (47)). We also included a term for the interaction of severe and

224 frequent defoliation treatments and a random effect of plot to allow for correlation in

225 observations from the same plot. Our varying-intercept/varying-slope model therefore included

226 four separate estimates of grand means (one for each cultivar), each of which represents an

227 estimate of performance for that cultivar across all defoliation treatment conditions, and four

228 treatment effect estimates (one for each cultivar) for frequent defoliation, severe defoliation, and

229 their interaction. Since these coefficients were drawn from distributions with estimated variance

230 components, the separate estimates were partially pooled towards their common mean, which

231 also was estimated from the data, a property that built in an automatic correction for multiple

232 comparisons among cultivars and obviated the need for arbitrary post-hoc adjustments such as

233 the Bonferonni correction (48). Finally, because growth data are naturally constrained to be

234 positive only and because we observed a pattern of variance increasing with the mean, we used a

235 gamma distribution to model our data, which naturally accounts for this nearly universal pattern

236 in biomass data. We used the standard log-link in our parameterization of the gamma regression

237 model, and thus our model coefficients represent multiplicative effects, and are reported on the

$238 \log$ link scale (46). Values greater than zero indicate positive effects on the response variable,

239 whereas values less than zero indicate negative effects. As in all cases where the log-link is used,

240 exponentiation of these regression coefficients returns the multiplicative effect which can be

241 naturally interpreted as a \% effect. 
We display treatment effects graphically by first plotting estimated fixed effect coefficients (i.e. frequency, severity and frequency X severity) centered on the median, and

244 include both a 50\% (thick) and a 95\% (thin line) uncertainty (credible) interval. These

245 coefficients represent the overall average effects of treatment or the interaction effect across all

246 cultivars. In addition, we graphically present the varying intercepts portion of our model, which

247 represents the overall average deviation of each cultivar from the grand mean across all cultivars,

248 and is thus naturally centered at zero. Here again, we include both 50\% (thick) and a 95\% (thin

249 line) credible intervals. The proportion of the credible interval above or below zero can be

250 interpreted as the Bayesian probability of that cultivar differing in response from the average

251 across all cultivars. In the case of root allocation, we further analyze all the pairwise contrasts

252 among cultivars ( $\mathrm{n}=6$ contrasts), by taking the difference between each coefficient at each

253 iteration of the MCMC sampler. These pairwise contrasts thus represent the differences between

254 each pair of cultivars in their overall root allocation, averaged across all treatment conditions.

255 We estimated these models in a Bayesian framework via Hamiltonian Monte Carlo in the

256 packaged "rstanarm” (v2.18.2) called from R (v3.5.3) via Rstudio (v1.1.463). Prior to analysis,

257 shoot and root production responses were standardized by dividing by their mean, resulting in

258 this case with response variables with scale $\sim \mathrm{O}(1)$ to facilitate faster sampling, and to help

259 specify weakly-regularizing $\operatorname{Normal}(0,1)$ priors for all treatment effects. For all models we

260 sampled the target (posterior) distribution with four chains of 2000 iterations each. Model

261 convergence was assessed via use of the R-hat $<1.01$ criterion (46) as well as by visual

262 inspection for chain blending and stability, and monitoring of the powerful diagnostics built into

263 rstanarm (i.e. divergent transitions and E-BFMI, citation). 
To understand the relative importance of defoliation treatment and cultivar compared with shoot production for predicting root production, we first fit a simple univariate regression model using only aboveground biomass from each subplot $(n=64)$ as a continuous covariate. We then refit our varying-intercepts/varying-slopes model while including shoot production as a continuous covariate alongside treatment and cultivar effects. We compare a Bayesian $\mathrm{R}^{2}$ metric between the models (49). Because the visual and $\mathrm{R}^{2}$ comparisons were so clear, we had no need to evaluate additional metrics of model predictive performance.

\section{Results}

273 Shoot production model

274 Average shoot production across all cultivars and treatment combinations in our study was $290 \mathrm{gm}^{-2}$, with the highest values observed in the infrequent severe defoliation treatment,

276 which averaged $384 \mathrm{gm}^{-2}$ (Fig 1). The fixed main effect estimate (on log-link scale, and reported 277 as posterior median $+/$ - posterior standard error) for severe defoliation was positive [0.28 +/-

2780.07 , Fig 2a], while the estimate for frequent defoliation was negative $[-0.18+/-0.08$, Fig 2a];

279 however, the interaction was negative as well [-0.25 +/- 0.15, Fig 2a], consistent with readily observable pattern (Fig 1) that it is the combination of severe + infrequent ( $4 \mathrm{wk})$ defoliation that

281 leads to over-yielding. Overall, we did not estimate substantial variability in shoot production

282 among cultivars across all treatments, although the upright cultivars (UF-Riata and Tifton-9) had

283 slightly higher production than the decumbent cultivars Argentine and Pensacola (Fig. 3a).

284 Fig. 1: Raw data $\left(\mathrm{gm}^{-2}\right)$ plotted as circles (shoots) and triangles (roots). Error bars show 285 mean biomass $\left(\mathrm{gm}^{-2}\right)+/-1 \mathrm{SE}$ for shoots (purple error bars) and roots (brown error bars). The 286 panels are faceted by treatment combinations: intensity of defoliation on top (lenient $15 \mathrm{~cm}$ or 287 severe $5 \mathrm{~cm}$ on top), and frequency of defoliation labeled on the right hand side ( $2 \mathrm{wk}$ or $4 \mathrm{wk}$ ). 288 The $\mathrm{x}$-axis groups responses by cultivar: $\mathrm{A}=$ Argentine, $\mathrm{P}=$ Pensacola, $\mathrm{T} 9=$ Tifton-9, and UF-R 289 = UF-Riata. 
Fig. 2: Fixed effects from varying-intercepts/varying-slopes Gamma regression model. 95\% (thin line) credible intervals for a) shoot production, $b$ ) root production and c) root allocation. Where the entire $95 \%$ credible interval falls above or below zero, we can interpret that as a $97.5+\%$ Bayesian probability of that coefficient having a positive or negative effect on the response, respectively.

\section{Fig. 3: Varying-intercepts from the Gamma regression model for root production.} Coefficients represent deviations of each cultivar ( $\mathrm{A}=$ Argentine, $\mathrm{P}=$ Pensacola, $\mathrm{T} 9=$ Tifton-9, and UF-R = UF-Riata) from the overall mean (fixed effect coefficient), and are thus naturally centered at 0 , where negative values represent lower than average performance, and positive values higher than average performance. Plots include a median (point), and 50\% (thick line) and $95 \%$ (thin line) credible intervals. Where the entire $95 \%$ credible interval falls above or below zero, we can interpret that as a $97.5+\%$ Bayesian probability of the cultivar having a higher or lower overall root production compared to the mean among all cultivars.

\section{Root production model}

We observed an average root production of $224 \mathrm{gm}^{-2}$, where mild defoliation treatments were the highest with $262 \mathrm{gm}^{-2}$ averaged across $2 \mathrm{wk}$ and $4 \mathrm{wk}$ defoliation frequencies, compared with severe defoliation with an average of $186 \mathrm{gm}^{-2}$ (Fig 1). The fixed main effect estimate for severe defoliation was negative $(-0.33+/-0.12$, Fig $2 b)$, with $>97.5 \%$ of posterior probability below 0 , while the main effects of frequent defoliation and the interaction of frequent $\mathrm{X}$ severe defoliation were highly uncertain, with $95 \%$ credible intervals spanning a similar range above and below zero. Average root production across all treatment groups varied by cultivar more substantially than shoot production (Fig 3b), with the decumbent cultivars Argentine and

316 Pensacola having greater root production than the upright cultivars UF-Riata and Tifton-9 (Fig

317 3b, Fig. 4). The greatest contrast was between Argentine and UF-Riata, which had a median 318 posterior difference of -0.36 on the log-link scale (Fig. 4), which represents a $30 \%$ lower root production. 
Fig. 4: Pairwise contrasts among each cultivar for the varying intercepts of the root allocation model. Key: $\mathrm{A}=$ Argentine, $\mathrm{P}=$ Pensacola, T9 = Tifton-9, and UF-R = UF-Riata. Plots include a median (point), and 50\% (thick line) and 95\% (thin line) credible intervals. Where the entire $95 \%$ credible interval falls above or below zero, we can interpret that as a $97.5+\%$ Bayesian probability of the first cultivar having a higher root allocation than the second 325 cultivar.

\section{Root allocation}

The fixed main effect estimate for severe defoliation on root allocation proportion was smaller uncertainty $(\mathrm{SE}=0.09$ versus 0.12$)$. This result represents a median estimate of $29 \%$ reduced allocation proportion to roots overall among cultivars and across both frequencies of defoliation with severe defoliation. Variation among cultivars was also similar to that observed

333 for root production (Fig 3c versus 3b), and thus we did not repeat the pairwise analysis since it 334 would convey redundant information.

339 (as in the analyses above), yielded a median $\mathrm{R}^{2}$ of 0.45 (Fig 5b). After removing the varying 340 intercepts/slopes by cultivar, this $\mathrm{R}^{2}$ value declined to 0.21 (see supplement), indicating that

341 accounting for cultivar identity doubles model fit. Close examination of Fig $5 \mathrm{~b}$ reveals that the

342 full model accounted for observed variations in root production quite well in the range of 100-

$343300 \mathrm{gm}^{-2}$ but severely underpredicted root production $>300 \mathrm{gm}^{-2}$.

344 Fig. 5: Shoot production does not predict root production. a) Predicted versus observed 345 scatterplot for root production as predicted by shoot production as an aboveground proxy, and b) 346 predicted versus observed scatterplot for root production as predicted by defoliation treatment, 
cultivar identity, and shoot production. For reference, the 1:1 line of "perfect fit" is plotted along with an in-sample median Bayesian $\mathrm{R}^{2}$ for both predictive models.

\section{Discussion}

Severe defoliation resulted in substantially greater shoot production when applied infrequently, but reduced root production among the bahiagrass cultivars. Averaged across all defoliation treatments, root production was also more strongly variable among cultivars than was shoot production. Thus, our results suggest that severe defoliation can trigger a tradeoff between aboveground and belowground allocation in managed subtropical pastures, and that the extent of this tradeoff depends in part on cultivar identity. Contrary to Georgiadis et al. (50) and Briske and Richards (28) who suggested that overcompensation is only likely to occur under waterlimitation, or given concomitant fertilization, we found significantly greater shoot production in response to severe defoliation under limited fertility and abundant soil water. Compared with mild defoliation, all cultivars exhibited this compensatory aboveground growth response to severe defoliation, but only when defoliation was applied infrequently (similar to Gates et al. (51)). However, the severe, but infrequent defoliation treatment that led to aboveground compensatory growth also suppressed root production. Thus, under low-input conditions, manipulating defoliation intensity and frequency to enhance forage production could evoke a tradeoff between shoot and root production.. Given the substantial literature demonstrating the importance of root carbon for maintenance of soil carbon pools $(17,18,22)$, these altered allocation patterns may have significant consequences for carbon cycling, and hence soil carbon sequestration services, in managed subtropical pastures. Moreover, use of simple aboveground proxies, such as leaf area/biomass, are unlikely to help constrain predictions of root production over large spatial scales. 
373 and Hamilton III et al. (52) where a single defoliation event stimulated root production and root

374 exudation, respectively. Moreover, the results reported here appear to conflict with

375 measurements of standing root biomass, root exudation rates, and their connections to microbial

376 biomass and soil carbon, across a system of long-term grazing exclosures on a similar pasture

377 site, as reported in Wilson et al. (22). These discrepancies suggest that root responses to short-

378 term grazing/defoliation events can strongly differ from season-long responses to grazing

379 regimens where both intensity and frequency of defoliation are expected to mediate plant

380 regrowth strategies (28). Moreover, long-term impacts of grazing exclusion in bahiagrass-

381 dominated subtropical pasture appear to involve pronounced phenotypic shifts in root:shoot

382 ratios, whereby absence of grazing favors lower root:shoot ratios, even when holding species

383 composition constant (22)On the other hand, Thornton and Millard (53) found that greater

384 severity of defoliation resulted in lower root mass (but greater $\mathrm{N}$ uptake per unit of root mass),

385 which is consistent with our findings. Meanwhile, Dawson et al. (30) report that weekly

386 defoliation over a growing season reduced root biomass compared with no defoliation, but

387 infrequent defoliation (every 8 weeks) had no effect. Our ambivalent findings on the role of

388 frequency of defoliation were thus somewhat surprising. Although we observed marked

389 suppression of variability of production under our severe + frequent treatment (see e.g., Fig 1),

390 root production was not markedly lower than in our severe + infrequent treatment. Overall, it

391 appears that in our system, severity, not frequency, of grazing is the more important determinant 392 of grass root production.

We observed substantial overall variability in root production among the grass cultivars.

394 However, it does not appear possible to predict cultivar-level belowground responses to specific 
grazing regimens based on observations of aboveground compensatory growth responses. As we decumbent types (Argentine, Pensacola), especially Argentine. On the other hand, all cultivars responded equally negatively to severe defoliation per se, and we observed similar total root production among all cultivars in the severe + frequent defoliation treatment, a scenario

401 reasonably representative of overstocked pastures. These results contradict the theory that more

402 grazing-tolerant genotypes, in our case Argentine and Pensacola, will have lower root production

403 as a consequence of greater post-grazing allocation to shoot regrowth $(28,30)$. Instead, it appears

404 that cultivars simply vary in root growth potential, but that severe defoliation, especially when

405 applied frequently, overwhelms this variability.

407 at fine spatial scales, at least in our experimental plots, with shoot production explaining only $8 \%$

408 of the in-sample variation in root production. By contrast, defoliation treatment and especially

409 cultivar identity appear to be very important for predicting root production in this system,

410 together accounting for roughly half the observed variance in root production. Gill et al. (14)

411 reported some success in predicting belowground NPP using an algorithm based only on

412 aboveground biomass and climate. However, their model consistently under-predicted root

413 production in more productive sites. Interestingly, we observed a similar severe underprediction

414 of root production in our more productive plots. Thus, we caution against using aboveground

415 proxies to predict belowground production, even within uniform and homogeneous ecosystems,

416 such as the planted pasture system where we worked. Our results suggest that knowledge of

417 grazing management and cultivar identity (in addition to species-level variations in composition, 
$418(54,55))$ are critical for generating accurate predictions of BNPP. Moreover, half of the variance

419 in belowground production was unexplained, even in our best model, suggesting significant

420 spatial heterogeneity in root system productivity that should be further investigated. Given recent

421 calls highlighting the importance of plant roots to future progress in biogeochemical modeling

422 and the quest to find reliable, scalable aboveground proxies to indirectly infer root processes

$423(36,37)$, our results are a sobering reminder of the challenges inherent to linking production

424 above and belowground. Accordingly, we suggest that a high priority for future research is to

425 study belowground root-rhizosphere processes using spatially-explicit sampling protocols

426 designed to maximize insight into heterogeneity at various spatial and temporal scales.

At the large scale, McNaughton (1998) (8) found that grazing intensity is uncorrelated

428 with standing root biomass or productivity in the Serengeti. However, in speciose natural

429 grasslands plant diversity may confer a stabilizing influence on root production $(55,56)$. By

430 contrast, monoculture pasture systems may respond more like mesocosm systems where high

431 defoliation intensity is associated with reduced root biomass (24). Moreover, since a large

432 proportion of managed grasslands are dominated by single species, variation in root production

433 among cultivars may represent an especially important component of diversity. Grazing

434 management may need to be matched to cultivar-level characteristics to optimize both forage and

435 root production, and establishment of planted pastures with multiple cultivars or genotypes may

436 be a viable, yet underappreciated, strategy for enhancing functional diversity. For instance,

437 combining upright and decumbent cultivars may introduce beneficial genotypic diversity that

438 could maximize utilization of both above and belowground resources via niche complementarity

$439(57,58)$. Additionally, cultivar-level variability suggests the potential for ecologists to collaborate 
440 with plant breeders to improve the sustainability of grassland agroecosystems by development of

441 improved forage cultivars selected for superior belowground traits.

442 Overall, our results suggest that intermittent severe defoliation can elicit much greater

443 shoot growth, but have neutral or negative effects on root production. It is possible that a more

444 moderate defoliation intensity than we tested would have led to similar stimulation of

445 aboveground compensation without the negative consequence for root production, a possibility

446 our study was not designed to test. Neither did our study consider impacts of defoliation on

447 rhizome biomass, but we note that our intent was to focus on root production since it appears to

448 be of greater relevance for soil carbon sequestration than other compartments of plant biomass

449 (17). Likewise, it is also possible that the lower fine root production we measured may have been

450 compensated for by greater rhizodeposition/root exudation. However, this possibility seems

451 unlikely given that rates of root exudation generally correlate to fine root surface area $(22,59)$.

\section{Conclusions}

Root production is critical for maintaining and increasing soil carbon pools in grassland

456 ecosystems, yet findings on the immediate and long-term effects of grazing on root production

457 remain variable. We hypothesized that severe defoliation, if applied infrequently, might lead to

458 overyielding of shoots, but would have only small impacts on root production. Moreover, we

459 hypothesized that cultivars selected for an upright growth habit would show less root production

460 overall, and would be more sensitive to defoliation stress. Overall, we found that severe

461 defoliation per se, regardless of frequency, suppressed root production, even as infrequently

462 applied severe defoliation increased shoot production. Thus, it appears that manipulating timing

463 and intensity of grazing to optimize forage production might evoke a negative tradeoff with root 
464 production. We did find support for the hypothesis that recently developed upright cultivars have

465 lower root production, and a lower root:shoot ratio, than widely naturalized decumbent cultivars.

466 The main limitation of our work is that realistic animal grazing management can differ from

467 experimentally imposed defoliation in two major ways: 1) grazing impacts will fall along a

468 spectrum of timing and intensity with more intermediate values than can be tested in a

469 randomized factorial experiment, and 2) grazers will return a certain fraction of consumed

470 carbon and nutrients in the form of manure and urine, creating heterogeneous patches of varying

471 nutrient availability. Moreover, we also caution that year-year variability in growing conditions

472 can induce variability in experimental effects. Ideally, we recommend long-term (3+ year) field

473 studies of controlled grazing (or defoliation) to begin to properly estimate the random effects of

474 such year-year environmental fluctuations.

475 In addition to recommending greater future consideration of intraspecific variations in

476 belowground responses to grazing, our work supports the need to perform season-long measures

477 of belowground productivity to obtain reliable estimates of belowground production that can be

478 used to parameterize soil carbon models. Our data also suggest that reliance on aboveground

479 proxies is, unfortunately, not justified at least for subtropical pastures. In addition, given the

480 limitations of observational and comparative work, we suggest that longer-term field

481 manipulations are necessary to evaluate a suite of grazing management scenarios across plant

482 composition treatments. Such experiments will significantly improve our ability to inform the

483 design and management of grassland agroecosystems for meeting aboveground (forage)

484 production goals while also optimizing belowground production, and thus soil carbon

485 sequestration and other soil carbon mediated ecosystem services such as nutrient retention and

486 water cycling (2). 


\section{Acknowledgements}

490 For significant assistance with field work and data collection we thank Carly Althoff, Jessica

491 Wilson, Trevor Caughlin, Anand Roopsind, James Estrada and Bryan Tarbox.

\section{References}

1. Scurlock JMO, Hall DO. The global carbon sink: a grassland perspective. Glob Change Biol. 1998;4(2):229-233.

2. Lal R. Managing soils and ecosystems for mitigating anthropogenic carbon emissions and advancing global food security. BioScience. 2010 Oct 1;60(9):708-21.

3. Gilmanov TG, Soussana JF, Aires L, Allard V, Ammann C, Balzarolo M, et al. Partitioning European grassland net ecosystem $\mathrm{CO} 2$ exchange into gross primary productivity and ecosystem respiration using light response function analysis. Agric Ecosyst Environ. 2007 Jun;121(1-2):93-120.

4. Cahill KN, Kucharik CJ, Foley JA. Prairie restoration and carbon sequestration: difficulties quantifying $\mathrm{C}$ sources and sinks using a biometric approach. Ecol Appl. 2009 Nov 17;19(8):2185-201.

5. McNaughton SJ. Ecology of a grazing ecosystem: the Serengeti. Ecol Monogr. 1985 Sep $1 ; 55(3): 259-94$.

6. Knapp AK, Blair JM, Briggs JM, Collins SL, Hartnett DC, Johnson LC, et al. The keystone role of bison in north american tallgrass prairie. BioScience. 1999 Jan 1;49(1):39-50.

7. Fuhlendorf SD, Engle DM. Restoring heterogeneity on rangelands: ecosystem management based on evolutionary grazing patterns. BioScience. 2001 Aug 1;51(8):625-32.

8. McNaughton SJ, Banyikwa FF, McNaughton MM. Root biomass and productivity in a grazing ecosystem: the Serengeti. Ecology. 1998 Mar 1;79(2):587-92.

9. Hamilton EW, Frank DA. Can plants stimulate soil microbes and their own nutrient supply? Evidence from a grazing tolerant grass. Ecology. 2001 Sep 1;82(9):2397-402.

10. McSherry ME, Ritchie ME. Effects of grazing on grassland soil carbon: a global review. Glob Change Biol. 2013;19(5):1347-57.

11. Balogianni VG, Wilson SD, Vaness BM, MacDougall AS, Pinno BD. Different root and shoot responses to mowing and fertility in native and invaded grassland. Rangel Ecol Manag. 2014 Jan 1;67(1):39-45.

12. Ziter C, MacDougall AS. Nutrients and defoliation increase soil carbon inputs in grassland. Ecology. 2012 Aug 21;94(1):106-16.

13. Cooley KD, Sollenberger LE, Blount AR, da Silva LS, Kohmann MM, Aryal P, et al. A Modified Ingrowth Core to Measure Root-Rhizome Accumulation of Perennial Forage Species. Agron J [Internet]. 2019 [cited 2019 Jul 24];0(0). Available from: https://dlsciencesocieties-org.lp.hscl.ufl.edu/publications/aj/articles/0/0/agronj2019.01.0051\#ref-14 
14. Gill RA, Kelly RH, Parton WJ, Day KA, Jackson RB, Morgan JA, et al. Using simple environmental variables to estimate below-ground productivity in grasslands. Glob Ecol Biogeogr. 2002 Jan 1;11(1):79-86.

15. Hui D, Jackson RB. Geographical and interannual variability in biomass partitioning in grassland ecosystems: a synthesis of field data. New Phytol. 2006 Jan 1;169(1):85-93.

16. Poirier V, Roumet $\mathrm{C}$, Munson AD. The root of the matter: Linking root traits and soil organic matter stabilization processes. Soil Biol Biochem. 2018 May 1;120:246-59.

17. Rasse DP, Rumpel C, Dignac M-F. Is soil carbon mostly root carbon? Mechanisms for a specific stabilisation. Plant Soil. 2005 Feb 1;269(1-2):341-56.

18. Sokol NW, Kuebbing SaraE, Karlsen-Ayala E, Bradford MA. Evidence for the primacy of living root inputs, not root or shoot litter, in forming soil organic carbon. New Phytol. 2019 Jan 1;221(1):233-46.

19. Johnson LC, Matchett JR. Fire and Grazing Regulate Belowground Processes in Tallgrass Prairie. Ecology. 2001 Dec 1;82(12):3377-89.

20. Klumpp K, Fontaine S, Attard E, Le Roux X, Gleixner G, Soussana J-F. Grazing triggers soil carbon loss by altering plant roots and their control on soil microbial community. $\mathrm{J}$ Ecol. 2009;97(5):876-885.

21. Hafner S, Unteregelsbacher S, Seeber E, Lena B, Xu X, Li X, et al. Effect of grazing on carbon stocks and assimilate partitioning in a Tibetan montane pasture revealed by $13 \mathrm{CO} 2$ pulse labeling. Glob Change Biol. 2012;18(2):528-538.

22. Wilson CH, Strickland MS, Hutchings JA, Bianchi TS, Flory SL. Grazing enhances belowground carbon allocation, microbial biomass, and soil carbon in a subtropical grassland. Glob Change Biol. 2018;24(7):2997-3009.

23. Augustine DJ, Dijkstra FA, Iii EWH, Morgan JA. Rhizosphere interactions, carbon allocation, and nitrogen acquisition of two perennial North American grasses in response to defoliation and elevated atmospheric CO2. Oecologia. 2011 Mar 1;165(3):755-70.

24. Bardgett RD, Wardle DA, Yeates GW. Linking above-ground and below-ground interactions: how plant responses to foliar herbivory influence soil organisms. Soil Biol Biochem. 1998 Dec;30(14):1867-78.

25. Milchunas DG, Lauenroth WK. Quantitative effects of grazing on vegetation and soils over a global range of environments. Ecol Monogr. 1993 Nov 1;63(4):327-66.

26. Madritch MD, Hunter MD. Phenotypic diversity influences ecosystem functioning in an Oak sandhills community. Ecology. 2002 Aug 1;83(8):2084-90.

27. Whitham TG, Bailey JK, Schweitzer JA, Shuster SM, Bangert RK, LeRoy CJ, et al. A framework for community and ecosystem genetics: from genes to ecosystems. Nat Rev Genet. 2006 Jul;7(7):510-23.

28. Briske D, Richards J. Plant responses to defoliation: a physiological, morphological and demographic evaluation. In: Wildland plants: physiological ecology and developmental morphology. Society for Range Management; 1995. p. 635-710.

29. Carman JG. Morphological Characterization and Defoliation Responses of Selected Schizachyrium scoparium Genotypes. Am Midl Nat. 1985;114(1):37-43.

30. Dawson LA, Grayston SJ, Paterson E. Effects of grazing on the roots and rhizosphere of grasses. In: Lemaire G, Hodgson J, Moraes A de, Nabinger C, Carvalho PC de F, editors. Grassland ecophysiology and grazing ecology [Internet]. Wallingford: CABI; 2000 [cited 2016 Feb 22]. p. 61-84. Available from: http://www.cabi.org/cabebooks/ebook/20003019246 
31. Interrante SM, Sollenberger LE, Blount AR, Coleman SW, White UR, Liu K. Defoliation management of bahiagrass germplasm affects cover and persistence-related responses. Agron J. 2009;101(6):1381.

32. Houborg RM, Soegaard H. Regional simulation of ecosystem CO2 and water vapor exchange for agricultural land using NOAA AVHRR and Terra MODIS satellite data. Application to Zealand, Denmark. Remote Sens Environ. 2004 Oct 30;93(1-2):150-67.

33. Li S, Potter C, Hiatt C. Monitoring of net primary production in California rangelands using Landsat and MODIS satellite remote sensing. Nat Resour. 2012;3:56-65.

34. Gu Y, Wylie BK, Bliss NB. Mapping grassland productivity with 250-m eMODIS NDVI and SSURGO database over the Greater Platte River Basin, USA. Ecol Indic. 2013 Jan;24:31-6.

35. Chen W, Zhang Q, Cihlar J, Bauhus J, Price DT. Estimating fine-root biomass and production of boreal and cool temperate forests using aboveground measurements: A new approach. Plant Soil. 2004;265(1-2):31-46.

36. Iversen CM, McCormack ML, Powell AS, Blackwood CB, Freschet GT, Kattge J, et al. A global Fine-Root Ecology Database to address below-ground challenges in plant ecology. New Phytol. 2017;215(1):15-26.

37. Malhotra A, Sihi D, Iversen C. The Fate of Root Carbon in Soil: Data and Model Gaps [Internet]. Eos. 2018 [cited 2019 Mar 28]. Available from: https://eos.org/meetingreports/the-fate-of-root-carbon-in-soil-data-and-model-gaps

38. Vendramini JMB, Sollenberger LE, Blount AR, Aguiar AD, Galzerano L, Valente ALS, et al. Bahiagrass cultivar response to grazing frequency with limited nitrogen fertilization. Agron J. 2013;105(4):938.

39. Beaty ER, Stanley RL, Powell J. Effect of Height of Cut on Yield of Pensacola Bahiagrass 1. Agron J. 1968 8/01;60(4):356-8.

40. Stanley RL, Beaty ER, Powell JD. Forage Yield and Percent Cell Wall Constituents of Pensacola Bahiagrass as Related to N Fertilization and Clipping Height. Agron J. 1977 6/01;69(3):501-4.

41. McNaughton SJ. Compensatory plant growth as a response to herbivory. Oikos. 1983 May 1;40(3):329-36.

42. Zhao W, Chen S-P, Lin G-H. Compensatory growth responses to clipping defoliation in Leymus chinensis (Poaceae) under nutrient addition and water deficiency conditions. Plant Ecol. 2008 May 1;196(1):85-99.

43. Silveira ML, Obour AK, Arthington J, Sollenberger LE. The cow-calf industry and water quality in South Florida, USA: a review. Nutr Cycl Agroecosystems. 2011 Apr 1;89(3):439-52.

44. Makkonen K, Helmisaari H-S. Assessing fine-root biomass and production in a Scots pine stand - comparison of soil core and root ingrowth core methods. Plant Soil. 1999 Mar $1 ; 210(1): 43-50$.

45. Doss BD, Ashley DA, Bennett OL. Effect of Soil Moisture Regime on Root Distribution of Warm Season Forage Species 1. Agron J. 1960 Oct 1;52(10):569-72.

46. Gelman A, Hill J. Data analysis using regression and multilevel/hierarchical models. Cambridge, England: Cambridge University Press; 2007. 651 p.

47. Schabenberger O, Jr TGGJPW, Kong F. Collections of Simple Effects and Their Relationship to Main Effects and Interactions in Factorials. Am Stat. 2000 Aug $1 ; 54(3): 210-4$. 
48. Gelman A, Hill J, Yajima M. Why we (usually) don't have to worry about multiple comparisons. J Res Educ Eff. 2012 Apr 1;5(2):189-211.

49. Gelman A, Goodrich B, Gabry J, Vehtari A. R-squared for Bayesian regression models. Am Stat. 2018 Dec 10;1-6.

50. Georgiadis NJ, Ruess RW, McNaughton SJ, Western D. Ecological conditions that determine when grazing stimulates grass production. Oecologia. 1989 Nov 1;81(3):316-22.

51. Gates RN, Hill GM, Burton GW. Response of Selected and Unselected Bahiagrass Populations to Defoliation. Agron J. 1999;91(5):787.

52. Hamilton III EW, Frank DA, Hinchey PM, Murray TR. Defoliation induces root exudation and triggers positive rhizospheric feedbacks in a temperate grassland. Soil Biol Biochem. 2008 Nov;40(11):2865-73.

53. Thornton B, Millard P. Effects of Severity of Defoliation on Root Functioning in Grasses. J Range Manag. 1996;49(5):443-7.

54. Steinbeiss S, Beßler H, Engels C, Temperton VM, Buchmann N, Roscher C, et al. Plant diversity positively affects short-term soil carbon storage in experimental grasslands. Glob Change Biol. 2008;14(12):2937-2949.

55. Tilman D, Reich PB, Isbell F. Biodiversity impacts ecosystem productivity as much as resources, disturbance, or herbivory. Proc Natl Acad Sci. 2012 Jun 26;109(26):10394-7.

56. Fornara DA, Tilman D, Hobbie SE. Linkages between plant functional composition, fine root processes and potential soil N mineralization rates. J Ecol. 2009;97(1):48-56.

57. Avolio ML, Chang CC, Smith MD. Assessing Fine-Scale Genotypic Structure of a Dominant Species in Native Grasslands. Am Midl Nat. 2011 Mar 25;165(2):211-24.

58. Chang CC, Smith MD. Resource availability modulates above- and below-ground competitive interactions between genotypes of a dominant C4 grass. Funct Ecol. 2014 Aug $1 ; 28(4): 1041-51$.

59. Jones DL, Nguyen C, Finlay RD. Carbon flow in the rhizosphere: carbon trading at the soil-root interface. Plant Soil. 2009 Aug 1;321(1-2):5-33.

\section{SUPPORTING INFORMATION}

S1 Fig. Diagram showing layout of plots. North is top of the page. Legend: Defoliation severity- Red $=$ Severe Defoliation $(5 \mathrm{~cm})$, Blue $=$ Lenient Defoliation $(15 \mathrm{~cm})$. Defoliation frequency $-2 \mathrm{wk}=$ Defoliated every 2 weeks, $4 \mathrm{wk}=$ Defoliated every 4 weeks. Bahia cultivar identity - A = Argentine, $\mathrm{P}=$ Pensacola, T9 = Tifton 9, $\mathrm{R}=$ UF-Riata.

S1 Table. Meteorogical data from our study site during study season. Ona Range Cattle Research and Education Center. Accessed from the Florida Automated Weather Network (FAWN), http://fawn.ifas.ufl.edu/.

60


bioRxiv preprint doi: https://doi.org/10.1101/763128; this version posted September 9, 2019. The copyright holder for this preprint (which was not certified by peer review) is the author/funder, who has granted bioRxiv a license to display the preprint in perpetuity. It is made available under aCC-BY 4.0 International license.

664

665

666

667

668

669

670

671

672

673

674

675

676

677

678

679

680

681

682

683

684

685

686

687

688

689

690

691 
a) Shoots

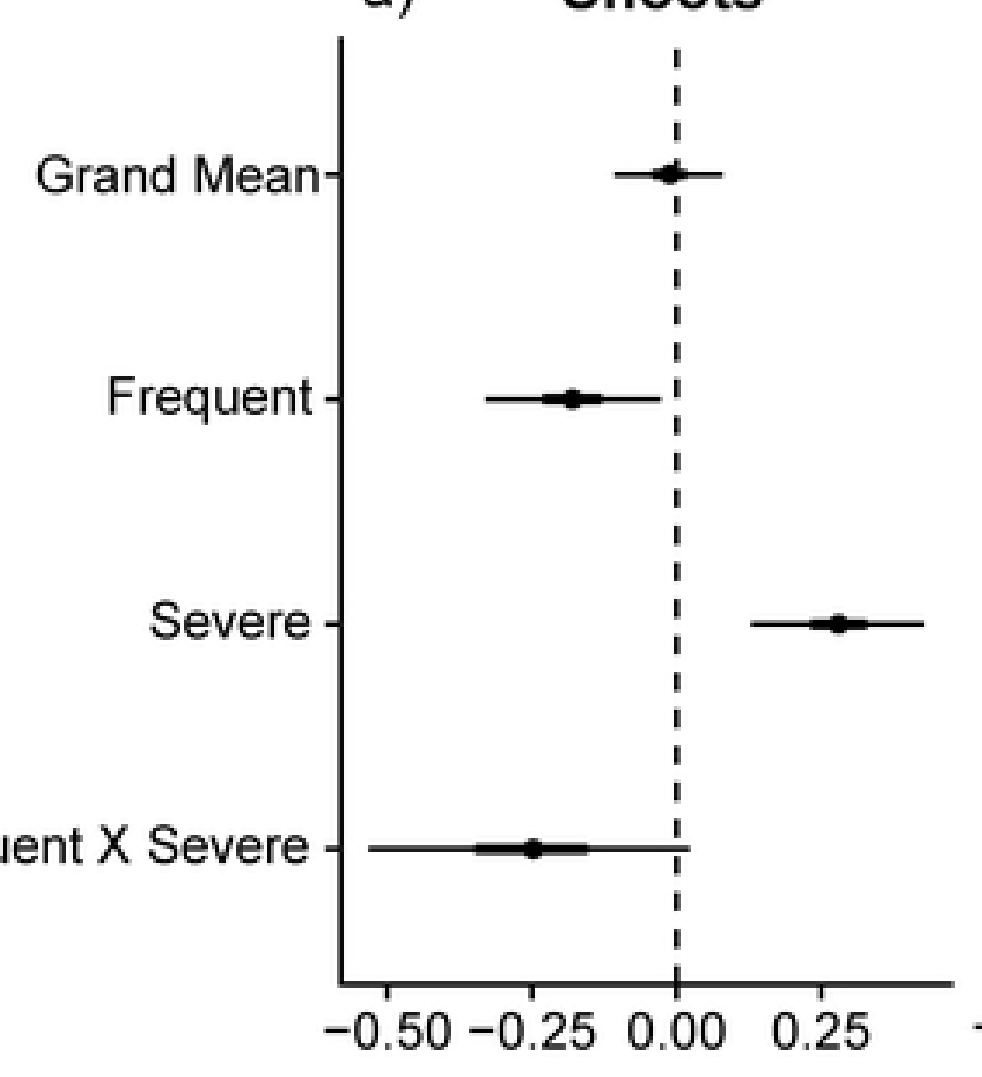

b) Roots

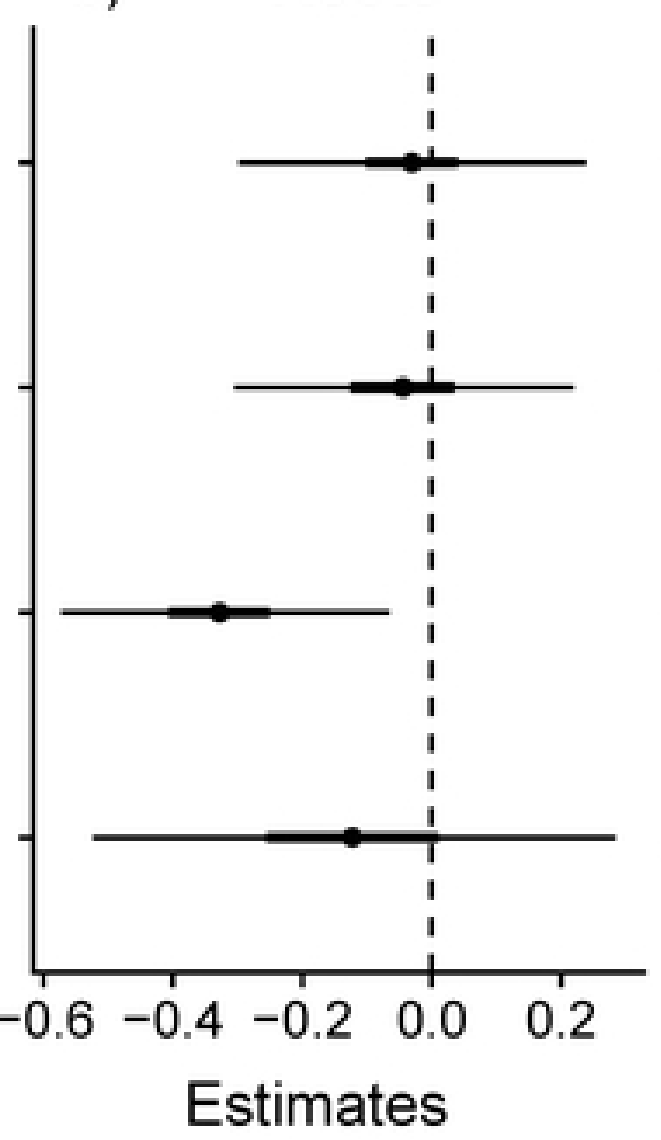

c) Root Allocation

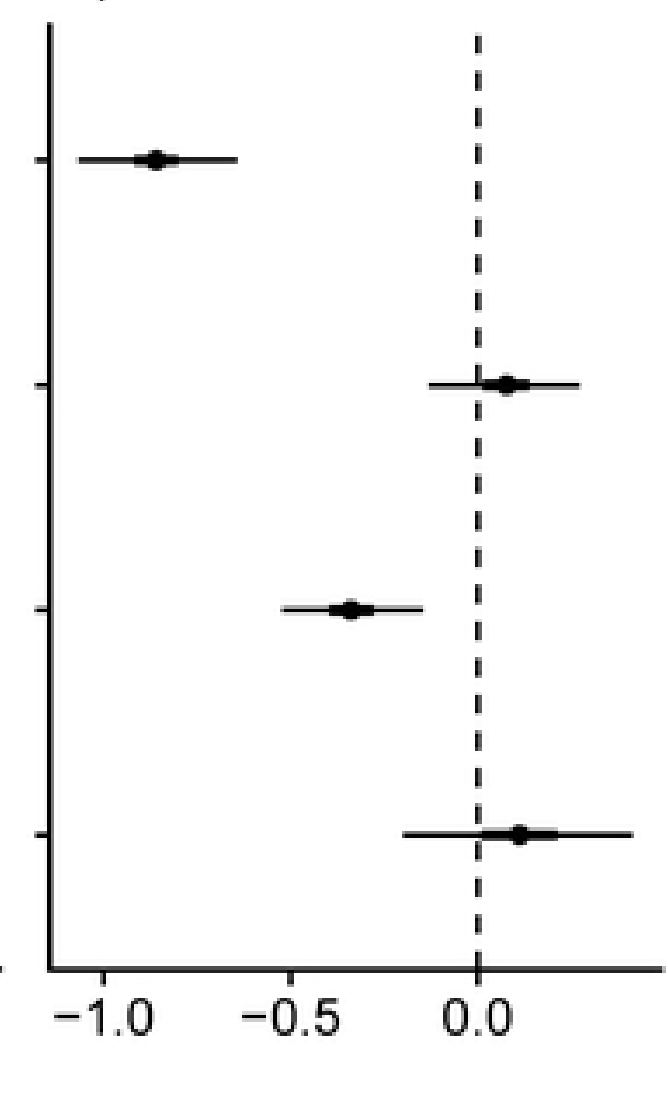

Figure 
a) Shoots

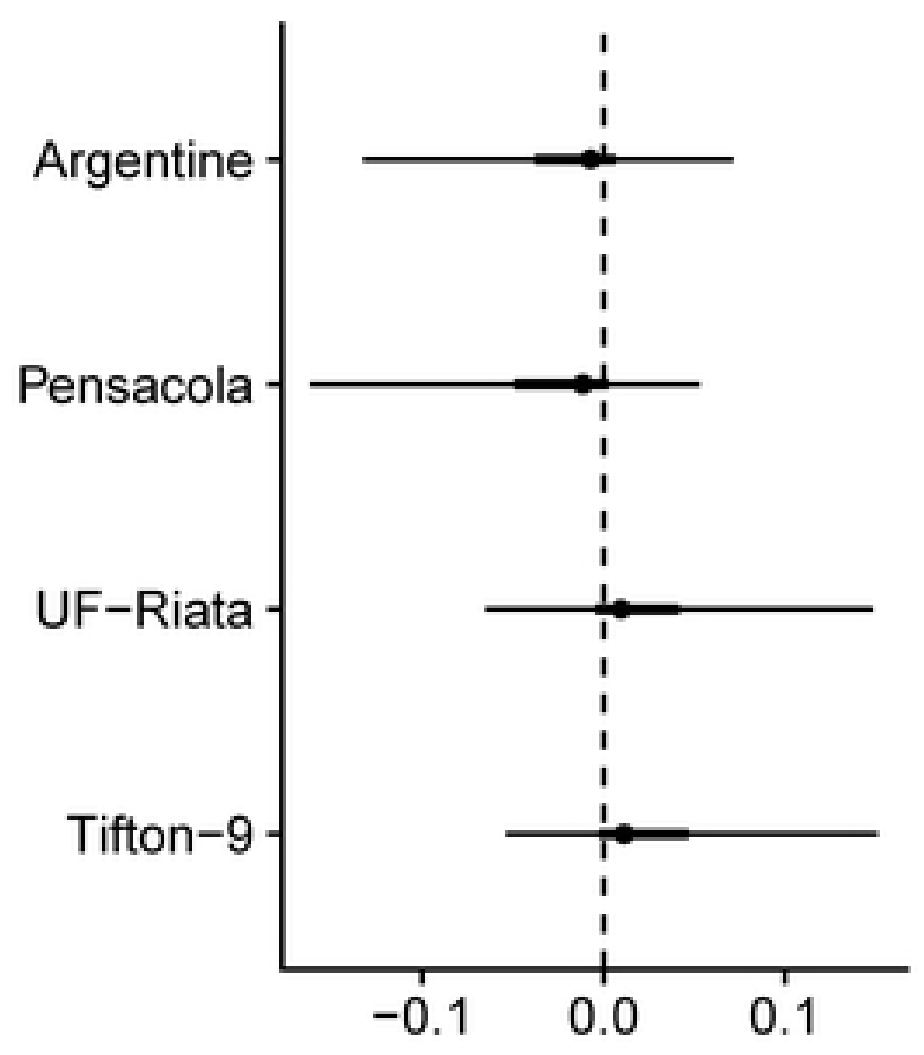

b) Roots

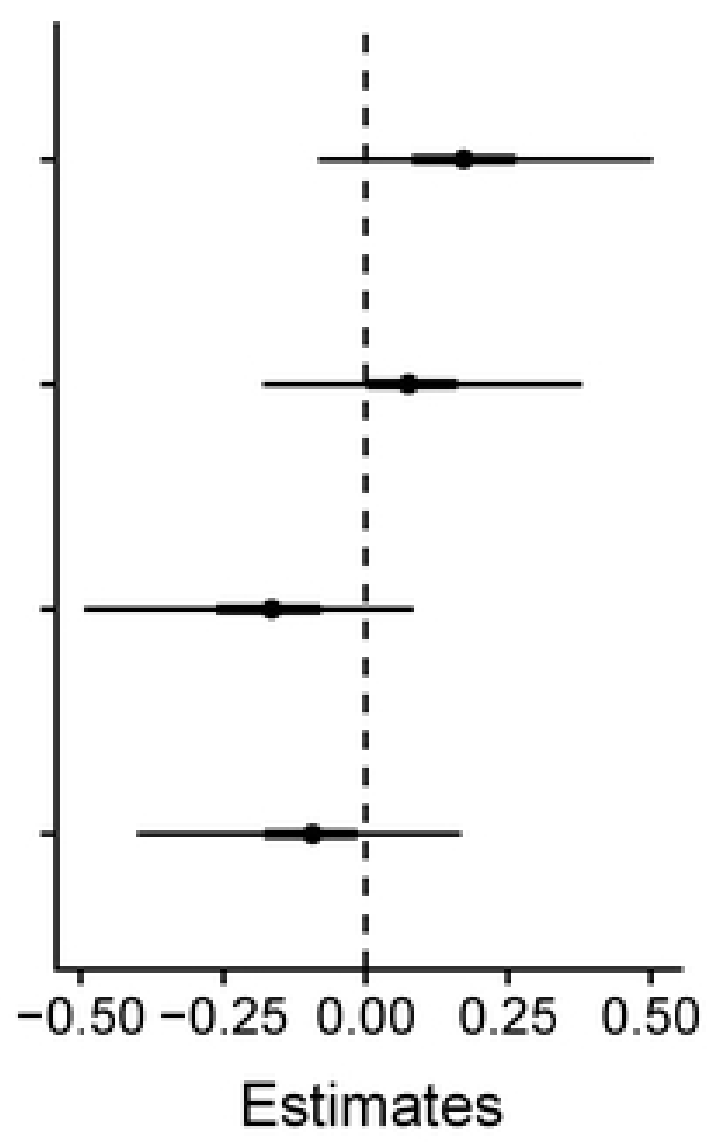

c) Root Allocation

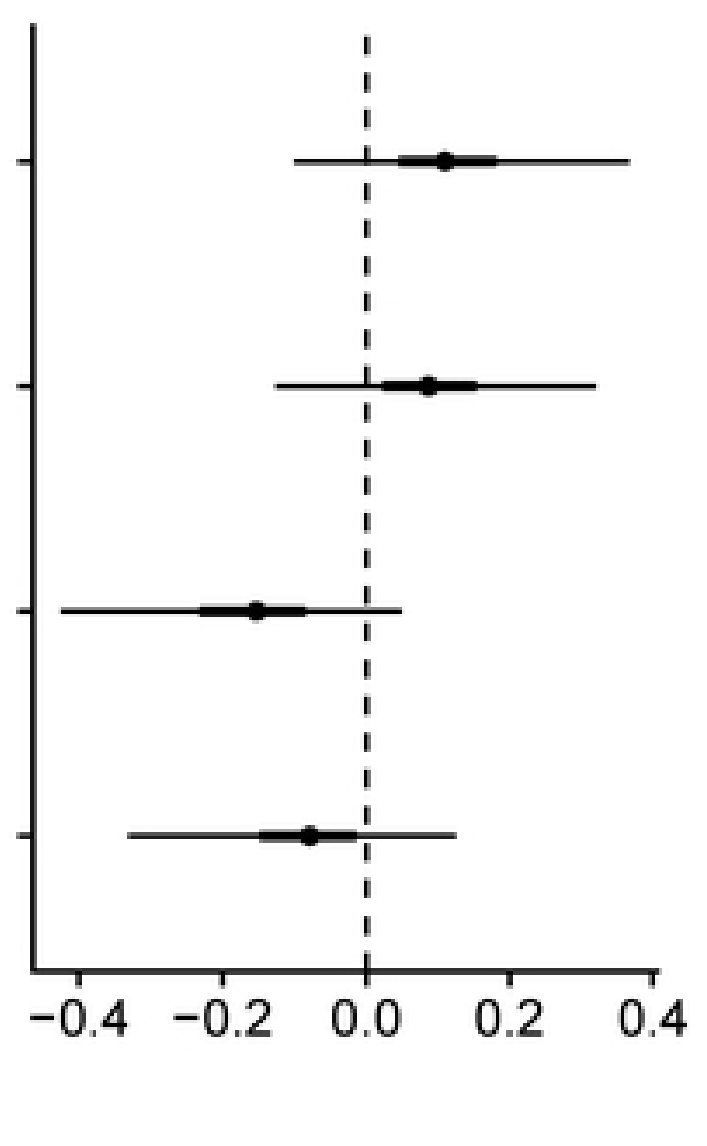

Figure 


\section{Pairwise Differences}

bioRxiv preprint doi: https://doi.org/10.1101/763128; this version posted September 9, 2019. The copyr $/$ ht holder for this preprint (which was not certified by peer review) is the author/funder, who has granted bioRxiv a license to display the prep int in perpetuity. It is made available

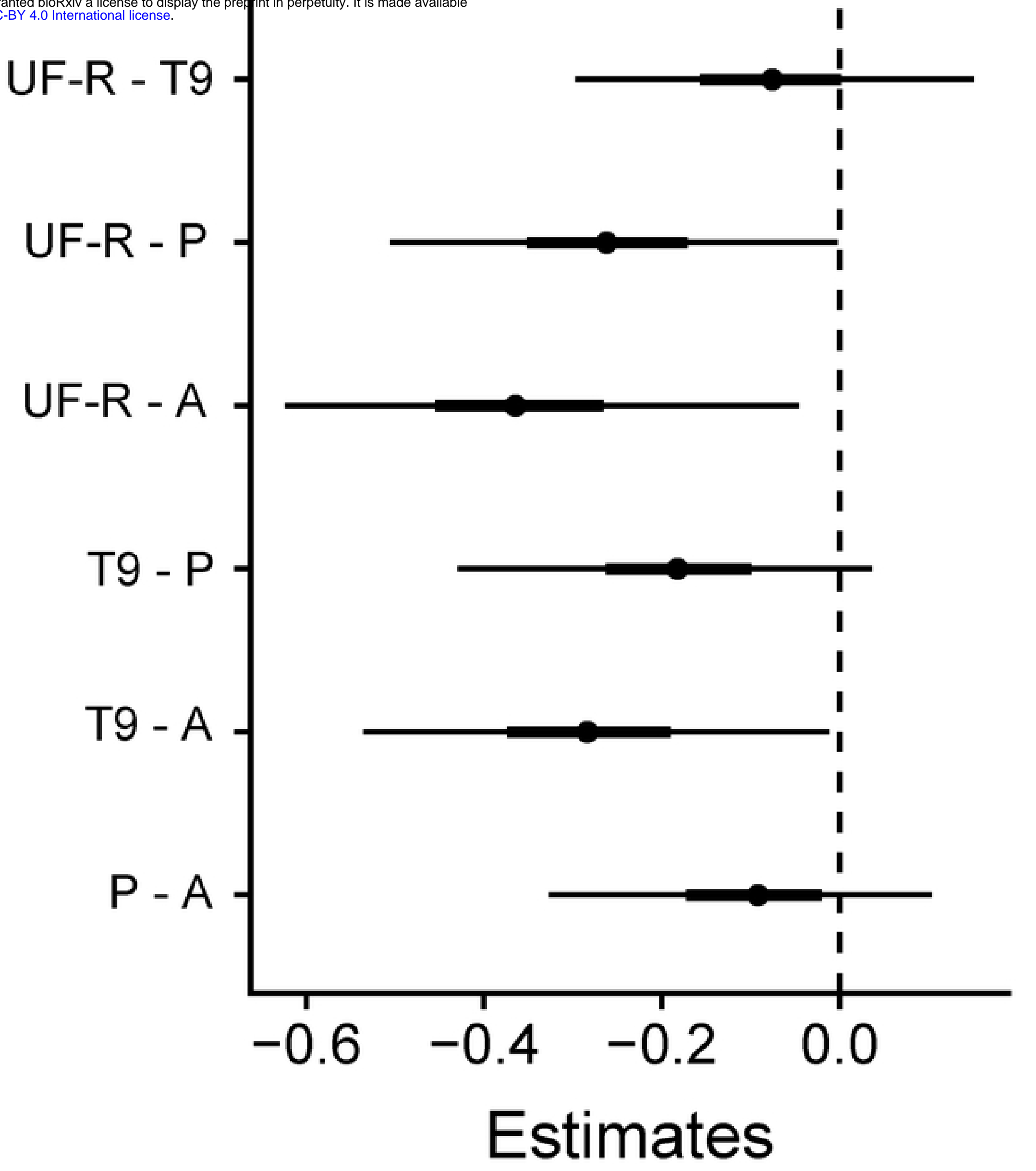

Figure 
a) Aboveground Proxy

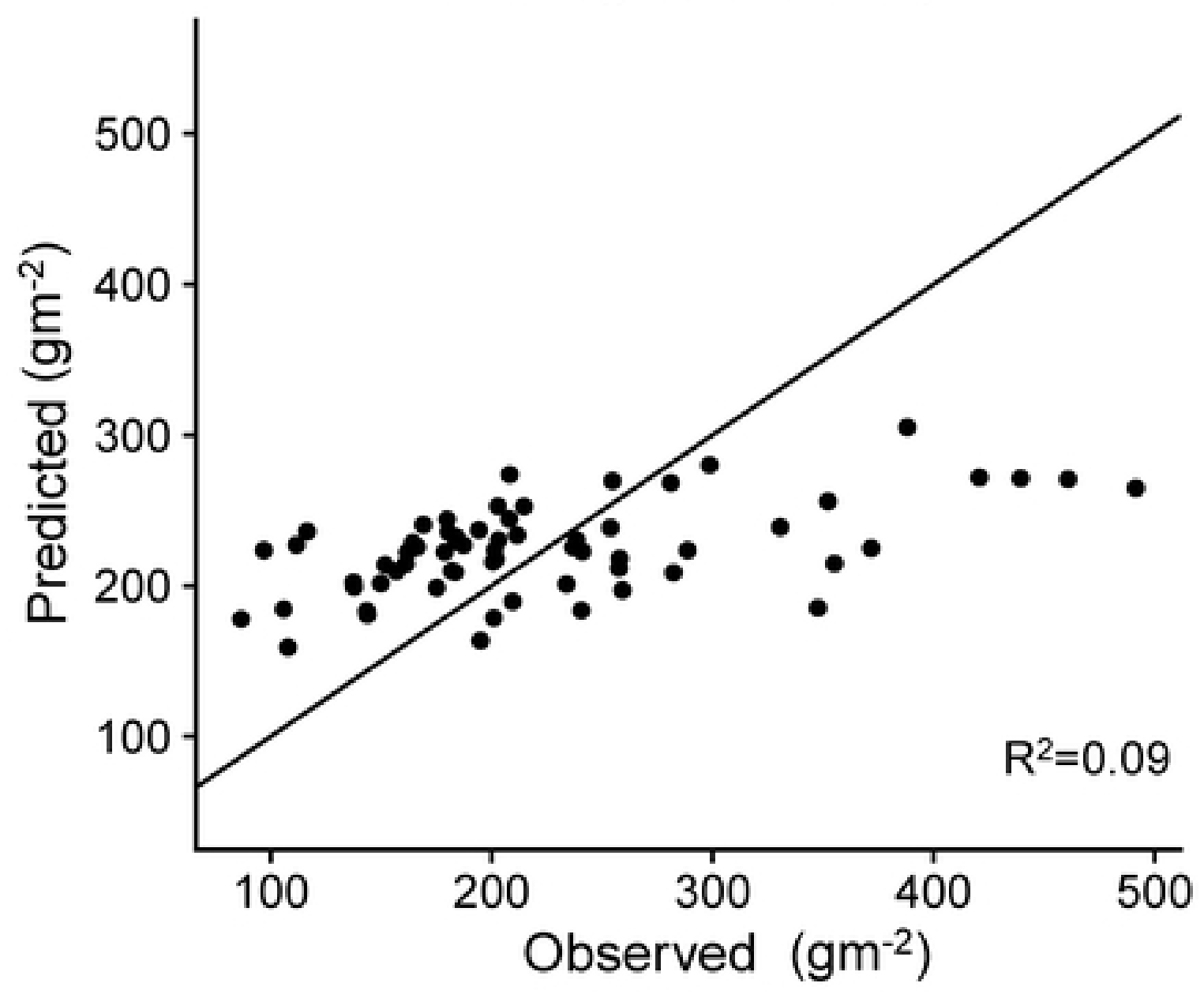

b) Aboveground Proxy + Treatment

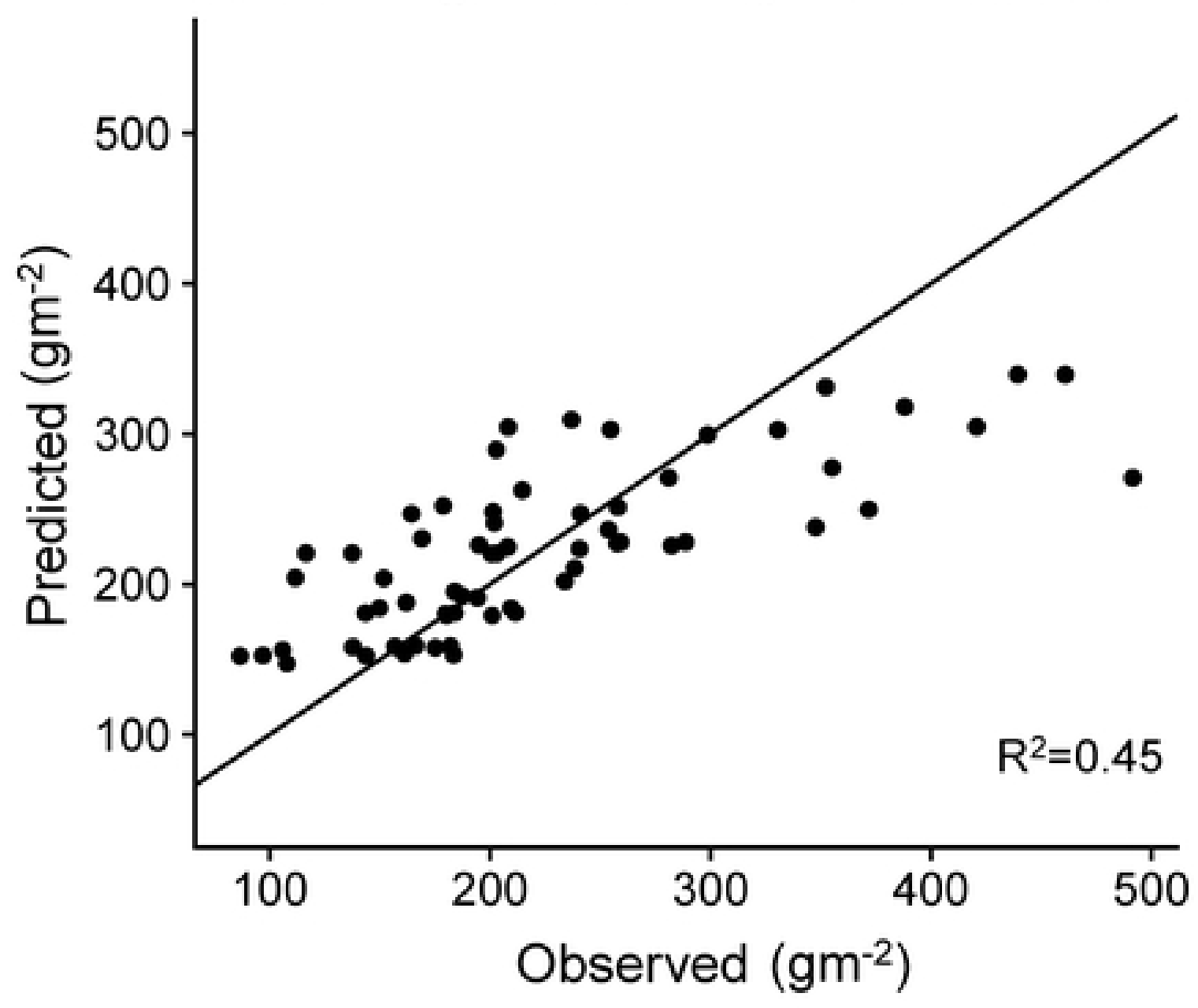

Figure 